infants drugs that may interfere with gut motility and indirectly influence the composition of the gut flora should be questioned.

The renal function in both infants remained normal and excluded haemolytic uraemic syndrome. $E$ coli isolates from one of the infant's stools were further investigated for production of toxins, including verotoxin, but these were not detected. Neither child had a colonoscopy performed and biopsy specimens for histological examination were therefore not available.

One of the infants had group $\mathrm{X} C$ difficile identified and the organism was a potent producer of both enterotoxin and cytotoxin. This group has caused an outbreak of antibiotic associated colitis in patients on oncology wards. ${ }^{4}$ The other infant had a highly toxigenic group W $C$ difficile identified-the usual groups found in newborn infants are A-D. ${ }^{4}$ Group $\mathrm{W}$ has been isolated from an adult with pseudomembranous colitis (unpublished data) and this organism was also found to be a high producer of toxins $\mathrm{A}$ and $\mathrm{B} .{ }^{6}$

It seems probable that $C$ difficile had clinical importance in these two infants. Both children appeared to respond to treatment with intravenous antibiotics, including metronidazole, which is effective against the organism. Possible pathogenic significance of $C$ difficile in the gut of infants with severe enterocolitis should not be discounted on the basis that this organism may also be found in stools of normal children in this age group. The use of typing schemes, often used for epidemiological purposes, may help elucidate the potential pathogenic role of $C$ difficile in individual patients and also determine whether specific antimicrobial treatment should be urgently instituted.

\section{References}

1 Reitra PJGM, Slaterus KW, Zanen HC, Meuwissen SGM. Clostridial toxin in facces of healthy infants. Lancet 1978;ii:319.

${ }^{2}$ Scopes JW, Smith MF, Beach RC. Pseudomembranous colitis and sudden infant death. Lancet 1980;i:114.

${ }^{3}$ Richardson SA, Brookfield DSK, French TA, Gray J. Pseudomembranous colitis in a 5-week old infant. Br Med J 1981:283:1510.

4 Tabaqchali S, Holland D, O'Farrell S, Silman R. Typing scheme for Clostridium difficile: application in clinical and epidemiological studies. Lancet 1984 ;i:935-8.

5 Heard SR, O'Farrell S, Holland D, Crook S, Barnett MJ, Tabaqchali $S$. The epidemiology of Clostridium difficile with use of a typing scheme: nosocomial acquisition and cross-infection among immunocompromised patients. J Infect Dis 1986;153: $159-62$.

6 Wren B, Heard SR, Tabaqchali S. Association between toxins $\mathrm{A}$ and $\mathrm{B}$ production and types of Clostridium difficile. J Clin Pathol 1987:40:1397-401.

Correspondence to Dr EH Price, Department of Microbiology, Queen Elizabeth Hospital for Children, Hackney Road, London E2 8PS.

Accepted 10 February 1988

\title{
AIDS encephalopathy with response to treatment
}

\author{
J MATTHES, ${ }^{*}$ L A WALKER,$\dagger$ J G WATSON,, AND A G BIRD $\dagger$ \\ Departments of *Paediatrics and TImmunology, Newcastle General Hospital, Newcastle upon Tyne
}

\begin{abstract}
SUMmARY A 3 year old boy who had acquired HIV infection transplacentally developed the classical features of AIDS encephalopathy, spastic diplegia and expressive aphasia. His computed tomogram showed cerebral atrophy. Treatment with zidovudine and weekly infusions of gammaglobulin led to considerable clinical improvement and an almost normal computed tomogram nine weeks later.
\end{abstract}

A boy was identified as HIV antibody positive at the age of 21 months after his mother presented and died of pneumonia due to Pneumocystis carinii. She was HIV antibody positive and had received two units of blood after the birth of her first child. The source of her infection remains unclear. The first child is well at age 6 and has no detectable HIV antibody. Our patient, the second child, is thought to have acquired HIV transplacentally.

The boy was born after a full term normal delivery, birth weight $3150 \mathrm{~g}$, and he received all conventional immunisations, including measles, without problem. His head circumference, weight, and length had grown along the 50th, 10th, and 10th centiles, respectively. His development was normal, and he had been walking normally since age 13 months and, aged 21 months, was starting to join words. The only clinical abnormality was moderate inguinal lymphadenopathy.

Initial investigation showed normal $\mathrm{T}$ lymphocyte subsets (fig 1) and a normal number of $T$ helper cells. He had a grossly raised IgG ( $37 \mathrm{~g} / \mathrm{l})$ concentration but no IgG virus antibodies (including measles 
and polio) were detected; this suggested impaired production of functional antibody. IgM isohaemaglutinins were present. Delayed type hypersensitivity skin tests with passive phytohaemagglutinin gave normal results.

At the age of 22 months he developed pertussis that was proved on culture. Despite early treatment from day seven of the illness with erythromycin, Bordetella pertussis could still be isolated at 28 days. Age 25 months he developed unilateral submandibular lymphadenitis with Streptococcus pyogenes cultured from the fauces. This responded rapidly to drainage (culture negative) and intravenous benzylpenicillin. His T4 cells were now depleted (fig 1) and IgG concentrations were diminished. One month later he developed a right lower lobe pneumonia with a heavy growth of Haemophilus influenzae from pharyngeal secretions. Despite physiotherapy and appropriate antibiotics there was little clinical response but high dose intravenous cotrimoxazole gave rapid resolution.

Over two weeks during this illness his speech rapidly regressed to expressive aphasia with only vowel sounds but with no cognitive impairment. He also rapidly developed a considerable spastic diplegia with inability to walk. A computed tomogram showed cerebral atrophy (fig 2). Sensory and motor nerve conduction studies gave normal results. His cerebrospinal fluid showed no white cells and normal concentrations of glucose and protein. No bacteria, fungi, or viruses were cultured. IgG antibodies to HIV were selectively increased in the cerebrospinal fluid. The antibody to albumin ratio given by the equation

$\frac{\text { [HIV in cerebrospinal fluid }}{\text { [Serum HIV-IgG] } \mathrm{IgG}] \quad \text { [Serum albumin] }}$

was 110 (upper limit of normal is 2), indicating production of HIV antibody in the cerebrospinal

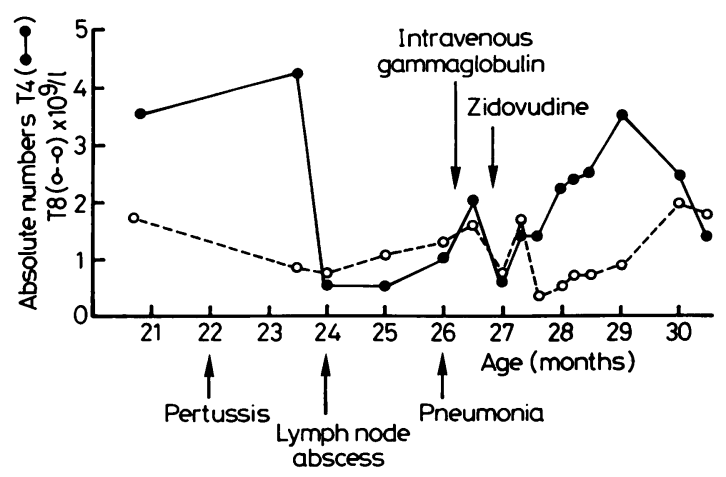

Fig 1 Changes in Tlymphocyte subsets.

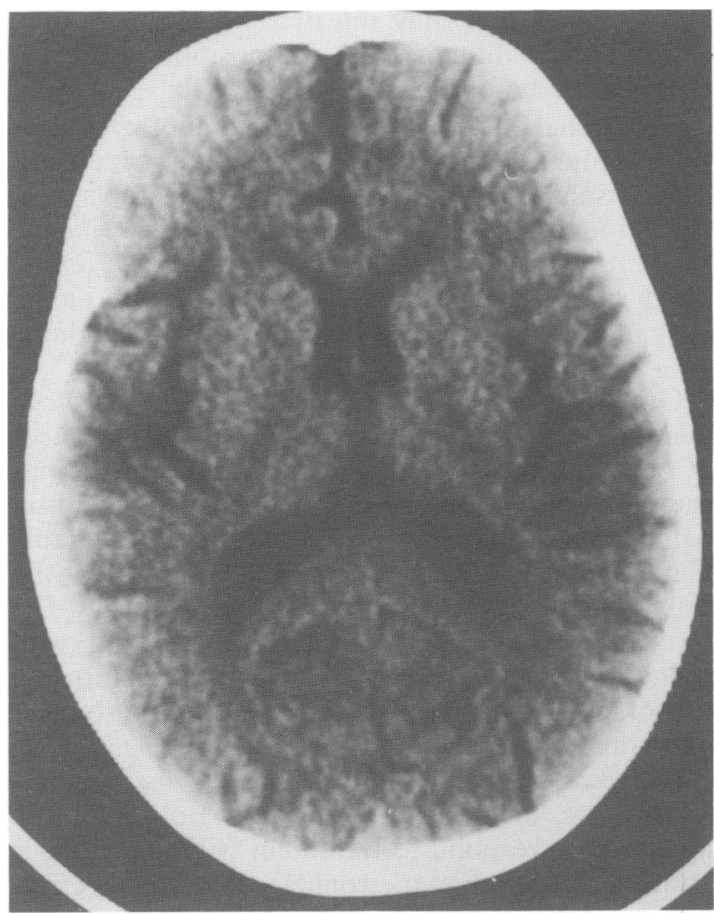

Fig 2 Initial computed tomogram.

fluid, and is evidence of HIV infection within the nervous system.

The patient was treated with intravenous gammaglobulin $300 \mathrm{mg} / \mathrm{kg}$. He was initially treated weekly because his IgG concentration was $14.2 \mathrm{~g} / \mathrm{l}$; he was also given oral zidovudine (Retrovir) $100 \mathrm{mg} / \mathrm{m}^{2}$ four times a day, equivalent to $16 \mathrm{mg} / \mathrm{kg} /$ day. This thymidine analogue selectively inhibits DNA chain elongation of the HIV but does not eradicate the viral genome from infected cells. Treatment with zidovudine and intravenous gammaglobulin every four weeks has continued for eight months. The intravenous preparation of zidovudine was given orally without acceptance problems and we have seen no haematological or neurological toxicity. A plasma profile of zidovudine showed a peak of $2.9 \mu \mathrm{M}$ of active drug with $10.9 \mu \mathrm{M}$ of glucuronide metabolite one hour after ingestion.

The boy has been cared for at home by his father and his general well being has remained good over eight months. He is now gaining weight normally. Spasticity has regressed allowing him to run unaided across the room, and his reflexes are now normal. $\mathrm{He}$ can articulate several single words. A repeat computed tomogram after nine weeks treatment showed considerable improvement (fig 3). His 


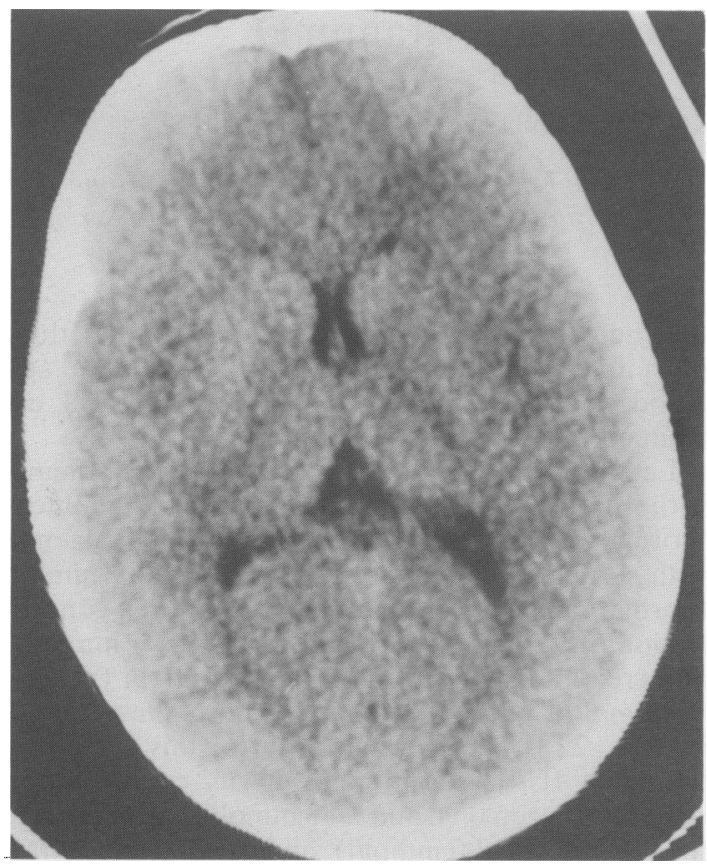

Fig 3 Computed tomogram after nine weeks treatment. This cut is at the same level as fig 2.

lymphocyte subsets initially became more normal but T4 concentrations fell 12 weeks after starting zidovudine (fig 1). These have now returned to normal (not shown in figure).

\section{Discussion}

AIDS encephalopathy in childhood usually presents with language deficits, developmental regression, pyramidal signs, and cortical atrophy. The encephalopathy may be static or progressive and, untreated, is associated with a very bad prognosis. ${ }^{1}$ Data have only recently become available that suggest that children with HIV encephalopathy may improve when treated with zidovudine with or without intravenous gammaglobulin (S Blanche and PA Pizzo. Abstracts presented at the Wellcome International Antiviral Symposium, Monte Carlo, 2-4 December 1987). There are reports of neurological improvement in adults treated with zidovudine. $^{2}$

The response to zidovudine may be dose dependent. Using $100 \mathrm{mg} / \mathrm{m}^{2}$ intravenously for two weeks followed by $100 \mathrm{mg} / \mathrm{m}^{2}$ orally four times a day, a
French group reported eight children with HIV encephalopathy of whom two became normal, three had a partial improvement, and three no real improvement ( $S$ Blanche. Abstract presented at the Wellcome International Antiviral Symposium, as above). These early results compare with the American experience of administering doses two to three times as great by continuous intravenous infusion. This was associated with noticeable improvement in all encephalopathic children, but unfortunately also with a high incidence of catheter related infections (PA Pizzo. Abstracts presented at the Wellcome International Antiviral Symposium, as above).

The immunological improvement could, however, be attributed in part to intravenous gammaglobulin. ${ }^{3}$ The fall in T4 numbers 12 weeks after starting zidovudine is consistent with recent reports. ${ }^{4}$ At this dose of zidovudine we saw no toxic effects with haematological indices, liver and kidney function remaining normal. Marrow suppression during zidovudine treatment, however, is as common in children as in adults. ${ }^{3}$

Zidovudine is an expensive drug in limited supply. As the dose depends on weight, more children than adults can be treated for the same cost. We believe this case should encourage others to use zidovudine in children with AIDS encephalopathy. Further studies will be required to determine the optimum dose, whether combination treatment of zidovudine plus acyclovir or gammaglobulin confers benefit, for how long treatment should continue, and whether neurological improvement is maintained.

We are grateful to Dr Yap and the Scottish National Blood Transfusion Service for the supply of gammaglobulin and to the Wellcome Foundation Ltd for supplies of Retrovir solution.

\section{References}

' Epstein LG, Sharer LR, Oleske JM, Neurologic manifestations of human immunodeficiency virus infection in children. Pediatrics 1986;78:678-87.

2 Yarchoan R, Brouwers P, Spitzer AR, et al. Response of human immunodeficiency-virus-associated neurological disease to $3^{\prime}$ azido-3'-deoxythymidine. Lancet 1987;i:132-5.

${ }^{3}$ Gupta A, Novick BE, Rubenstein A. Restoration of suppressor $T$ cell functions in children with AIDS following IV gammaglobulin treatment. Am J Dis Child 1986;140:143-6.

${ }^{4}$ Fischi MA, Riceman DD, Grieco MH. The efficacy of AZT in the treatment of patients with AIDS and ARC. N Engl J Med 1987;317:185-91.

Correspondence to Dr JG Watson, Department of Paediatrics, Newcastle General Hospital, Westgate Road, Newcastle upon Tyne NE4 6BE.

Accepted 30 December 1987 